\title{
ALEKSANDER PECZENIK (1937-2005)
}

\author{
Robert Alexy \\ Universidad de Kiel
}

$\mathrm{A}$

leksander PECZENIK murió en Lund, Suecia, la mañana del 19 de septiembre del 2005. Con su muerte, la comunidad de teóricos y filósofos del Derecho perdió a un académico excepcional; y para aquellos de nosotros que teníamos el privilegio de contar con su amistad, perdimos además a un maravilloso ser humano.

Aleksander Peczenik había nacido en Cracovia, Polonia, el 16 de noviembre de 1937. En el año 1955 comenzó sus estudios de Derecho en la Jagiellonian University de Cracovia. Kazimierz OpaleK fue por aquel entonces uno de sus maestros. PeczeNIK completó sus estudios en un tiempo record. En 1960, el mismo año en que contrajo matrimonio con Irena Nowak, obtuvo el grado de Master en Derecho (LL.M.); en 1963, el grado de doctor en Derecho (Iur. Dr.) y en el año 1966 fue habilitado como profesor de Derecho. A la edad de 29 años obtenía así una plaza como profesor en el Instituto de Metodología del Derecho de Katowice, Instituto que, por entonces, estaba integrado en la Universidad de Cracovia.

Tres años después, en 1969, deja Polonia y lo hace sin tener puesto alguno en Occidente; un mundo, por aquella época, muy diferente al suyo. No obstante, su energía, inteligencia, determinación y perseverancia le ayudaron a abrirse camino. Escribió cerca de 800 solicitudes, de las cuales recibió dos ofertas concretas: una venía de Suecia, la otra de Alemania. Aleksander PECZENIK optó por ir a Estocolmo y, aun cuando nuevas ofertas se le presentaron, se mantuvo fiel a su primera decisión. Alf Ross, quien posteriormente escribiera la presentación a su libro Essays in Legal Theory, publicado en 1970, fue una de las personas que más le ayudaron en el proceso de incorporación a Escandinavia. De 1969 a 1975 fue profesor asistente de filosofía del Derecho en Estocolmo. Además de impartir clases de filosofía del Derecho, se dedicó con tanto afán al estudio del Derecho sueco que aprobó el examen de acceso a la abogacía en Suecia en el año 1975; en ese mismo año comenzaba además su trabajo como catedrático (Senior Lecturer) en la facultad de Derecho de Lund. Llegaba así, tras dejar atrás su natal Cracovia, a su segundo destino. En 1978 sucedió a Tore STRÖMBERG y a Karl OliveCrona como profesor de "Jurisprudence and Law and Computers", en Lund. Desde el 2003 al 2004, PECZENIK ocupó la posición de profesor investigador Samuel Pufendorf, jubilándose en el año 2004. Tiempo atrás, en el 1983, había obtenido el título de doctor en Filosofía ( $P h . D$.), una muestra más de su tenaz actitud para seguir aprendiendo en cualquier ámbito imaginable. En 1987, la facultad de Derecho de la Universidad de Lund le otorgó el título de doctor bonoris causa y en 1991 fue nombrado miembro extranjero de la Academia Finlandesa de las Ciencias. 
Tras su jubilación en Suecia, Aleksander PECZENIK se embarcó hacia una nueva aventura en su natal Cracovia. Esta vez, como profesor de Argumentación jurídica y de Retórica en la Universidad de Szczecin. Esta nueva etapa, que todos esperábamos que culminara en el 2007 con la celebración bajo su presidencia del $23 .^{\circ}$ Congreso Mundial de la IVR en Cracovia — la ciudad de su origen biográfico e intelectual-, fue, sin embargo, interrumpida por su repentina muerte. Desafortunadamente PECZENIK se vio privado de la posibilidad de cerrar este ciclo de su vida.

Aleksander PECZENIK no sólo conjugó la maestría en su campo con el permanente entusiasmo de un estudiante, sino que también desempeñó con eficacia y seriedad los cargos de dirección que se le otorgaron. Fue así vicepresidente de la Asociación Nacional de Filosofía del Derecho y Filosofía Social (IVR) y, desde el año 2003 hasta el año de su muerte, su presidente.

No solamente aportó su talento organizativo y sus sugerentes ideas a la IVR, sino que además fue director editorial de la colección "Law and Philosophy Library", publicada por Kluwer, co-editor de Associations y miembro del Comité editorial de los Archives for Philosophy of Law and Social Philosophy, así como también de Ratio Juris.

La obra académica de Aleksander PECZENIK se inscribe en líneas generales en la tradición analítica polaca en filosofía del Derecho; tradición caracterizada por su profundo y extenso interés en la lógica, la epistemología y la metodología. PECZENIK nunca renunció al rigor analítico al intentar llevar a la filosofía del Derecho hacia nuevas direcciones. Tres puntos centrales permiten caracterizar sus contribuciones a este campo.

En primer lugar, se encuentra su teoría de la transformación o de los "saltos". El conocimiento, generalmente, viene respaldado por razones que no suponen aquello que se conoce. En la medida en que esto es así, el conocimiento, y con él la ciencia, poseen una estructura profunda no deductiva. Para ejemplificar lo anterior, en The basis of legal justification (1983), Aleksander PECZENIK introduce una extensa clasificación, así como un profundo análisis de las transformaciones necesarias en el Derecho. Gracias a estos esfuerzos contamos ahora con una suerte de mapa de los pasos creativos indispensables tanto para el conocimiento como para el razonamiento jurídicos.

Dar un paso o un "salto" es una cosa; su justificación, corrección u objetividad otra muy distinta. Con el fin de dar respuesta al problema de la justificación, Aleksander PECZENIK desarrolló - y éste sería el segundo punto central de su trabajouna teoría de la coherencia en el Derecho, que es una de las teorías sobre la coherencia más significativas que se hayan elaborado acerca del conocimiento jurídico. Una presentación breve e ilustrativa puede encontrarse en su ensayo «A coherence Theory of Juristic Knowledge» en On Coherence Theory of Law (1998). El tercero de los puntos principales que caracterizan el pensamiento de Aleksander PECZENIK descansa en lo que puede caracterizarse como sistematización reflexiva. Este elemento, que aparecía ya en sus primeros escritos, se manifiesta de forma más clara y notable en su trabajo más reciente. En este sentido, una brillante muestra de ese talento o capacidad de sistematización reflexiva podemos encontrarla en Vad är rätt (1995), así como también en su último gran trabajo, Scientia Juris. Legal Doctrine as Kwnoledge of Law and as a Source of Law (2005), que constituye el cuarto volumen de un trabajo colectivo titu- 
lado $A$ Treatise of Legal Philosophy and General Jurisprudence, editado por Enrico PATTARO. Este último volumen, donde muestra con detalle su gran «Pasión por la Razón» - de ahí el título de la presentación que de su propio trabajo había hecho en el volumen de Luc. J. Wintgens, The Law in Philosophical Perspectives del año 1999-, es el regalo que Aleksander PECZENIK nos hizo, justo el mismo año de su fallecimiento.

Mientras escribo estas líneas no puedo evitar levantar la vista y mirar el asiento que Aleksander PECZENIK ocupaba en mi despacho durante nuestras discusiones con ocasión de sus visitas a Kiel. Nuestro primer encuentro fue en Retzhof, cerca de Graz, donde la Sección Austriaca de la IVR había celebrado un Simposio sobre "Philosophy and Sciences as Basis for Jurisprudence". Y es gracias a una fotografía de POZNAN, que aparece fechada y que fue hecha por Zygmunt Ziembiñski, que puedo recordar que ese primer encuentro fue el 9 de mayo de 1979. La primera carta que recibí de Aleksander PECZENIK es del 14 de mayo de 1979 y la última del 30 de agosto del 2005.

Tuve, sin embargo, la fortuna de que nuestro contacto a lo largo de todos esos años no se limitara a una relación epistolar. La conferencia en Retzhof fue el principio de una larga serie de reuniones en Lund, Gotinga, Kiel, entre otros muchos lugares alrededor del mundo. Nuestro último encuentro tuvo lugar en Granada, en mayo del 2005, con motivo del 22. ${ }^{\circ}$ Congreso Mundial de la IVR. Todos esos encuentros fueron especiales, muchos incluso apasionantes, pero uno de ellos fue tan extraordinario que invito al lector a prestar especial atención a lo que a continuación voy a relatar: me refiero al encuentro que tuvimos en Amsterdam con Aulis AARNIO en septiembre de 1980. Fue en Amsterdam en donde completamos el trabajo que quedaba pendiente para cerrar nuestro artículo conjunto «The Foundations of Legal Reasoning», publicado en tres secciones en Rechtstheorie en 1981. La idea de este proyecto había surgido en diciembre de 1979 en un Simposio en "Argumentation in Legal Science" en Helsinki.

Una vez que acordamos llevar a cabo el proyecto, fue Aleksander PECZENIK quien, como era propio de él, volcó todas sus energías para sacarlo adelante. «Máxima urgencia» fueron las palabras que escribió en un folio en el que yo había trazado el 12 de diciembre de 1979 un diagrama acerca de las relaciones entre nuestras teorías. A esas palabras añadió: «enviar el primer borrador a R. A. a más tardar el 25.12.79». Y así lo hizo. Tras una serie de reuniones y ante lo que parecía ser un interminable número de cartas, había llegado ya el momento oportuno. Ninguno de nosotros teníamos especial interés en asistir a la conferencia que se había organizado en Amsterdam. Aleksander PECZENIK apareció en Gotinga en su BMW 320i de color rojo y desde ahí hicimos el viaje en coche más veloz que jamás en mi vida he realizado. Durante todo el trayecto hacia Amsterdam no dejamos de discutir problemas de teoría del Derecho. Aulis AARNIO estaba ya en Amsterdam, de forma que nada más llegar al hotel Destine, donde nos alojamos, inmediatamente nos pusimos a trabajar. Continuamos trabajando arduamente durante tres días sin interrupciones salvo por breves lapsos de tiempo para dormir. El entusiasmo de Aleksander PECEZNIK nos llevó a estar tan contentos como agotados. Al tercer día dejamos Amsterdam sin haber visto nada de la ciudad ni asistido a la conferencia, pero con un borrador de nuestro trabajo que se acercaba bastante a su versión definitiva.

Lo sucedido en Amsterdam no es más que un ejemplo de la extraordinaria habilidad que tenía Aleksander PECZENIK para inyectar gran entusiasmo y motivación en 
las personas, así como para hacer que los proyectos fueran rodando. No es por casualidad que estuviera presente cuando —en agosto de 1982, durante unas vacaciones que Robert S. Summers, Enrico PATTARO y él pasaron en los Dolomitas acompañados de sus esposas - surgiera la idea del Círculo de Bielefeld, una asociación de teóricos del Derecho cuyo trabajo iba a estar dirigido a un análisis comparativo de la investigación metodológica. Bajo la dirección de Robert SumMERS y de Neil MACCORMICK, y tras una serie de reuniones en el Centro de Estudios interdisciplinarios de Bielefeld y otras 10 reuniones mantenidas en otros lugares, el Círculo de Bielefeld produjo, en 1991, Interpreting Statutes y, en 1997, Interpreting Precedents.

No fue una sorpresa para nadie que una persona con sus habilidades su visión, su capacidad comunicativa y su energía llegase a ser presidente de la IVR. Transfirió a la organización su ilimitada energía y compromiso. Mencionaré sólo uno de sus muchos logros: la próxima aparición de la Encyclopaedia of Jurisprudence, Legal Theory and Philosophy of Law de la IVR. Esta base de datos electrónica, de extensión mundial, de teoría y filosofía del Derecho, constituye uno de los legados permanentes que nos deja Aleksander PECZENIK.

Perder a un amigo como Alek es motivo de tristeza. Irremediablemente esa tristeza va unida a la más profunda gratitud. Mi vida se hubiera visto privada de algo fundamental de no haberle conocido, y nuestro mundo hubiera sido un lugar más pobre si Aleksander PECZENIK no hubiera formado parte de él.

(Trad. Kira Ciófalo) 